I AM afraid I neither realise the basis nor appreciate the strength of Mr. Lauwerys' clearly implied prophecy that fruitful developments of biology and psychology-by which I trust he means the study of behaviour, since that is the matter under discussion -depend largely on the acceptance of teleological ideas in general, and the concept of purpose in particular. The issues as they are stated are unfortunately vague, and difficult to discuss in a short space, but if prophecies in these matters are of any value, it seems to me that the futures of these subjects depend only upon the further recognition of sensible problems, capable of investigation, within the fields of objective fact to which they refer. The criterion of objective fact, from the point of view of science, is that it constitutes a datum that is public in the sense defined by Hogben, and is capable of expression without fear of ambiguity.

The methods by which facts such as these may be analysed can be many and varied, provided they conform to the demands of proper scientific procedure. Since it is perfectly legitimate to regard 'explaining' in science as being synonymous with generalising and hypothesising, it seems to me idle to contend that in science 'interpretations' and 'explanations' are any more subjective than the primary data to which they relate. In this connexion it is well to remember that both opponents and protagonists of classical behaviourism agree that this school of psychology breaks down as a final philosophy because of its indefensible but necessary assumption that the objective facts of experience are unrelated to subjective experience. But in any event the whole question raised by Mr. Lauwerys is completely irrelevant. Determinism, if need be, could flourish in the thickest undergrowths of a solipsist's mind.

Mr. Lauwerys states that it is the teleologist who insists that the future is immanent in the present. In so far as the merits of a deterministic hypothesis are weighed by its value for purposes of prediction, this, by definition, is also part of the determinist's creed. Mr. Lauwerys is simply making a false antithesis. Merely agreeing that the prediction of the future is a worthy aim of science does not give to teleology any virtue that makes it necessary in scientific research.

I am not prepared to say whether or not the category of final causation is a weapon of scientific analysis. If it is, Mr. Lauwerys and those who agree with him have the task of showing that it can operate as such. At the moment, those who conduct their investigations according to everyday deterministic methods, without any appeals to teleology, are doing most, if not all, of the work of extending our reliable knowledge of phenomena.

The Writer of the Article.

\section{Effect of Ultra-Centrifuging on the Cells of the Root-Tip of the Bean}

Root-TIPs of the bean were centrifuged in the Beams ultra-centrifuge at approximately 400,000 times gravity for twenty minutes. The effect is shown diagrammatically in Fig. 1. Fig. $\mathbf{l}(a)$ is a control cell showing the normal distribution of the cytoplasmic components and inclusions. Fig. $\mathrm{I}(b)$ represents an ultra-centrifuged cell showing the redistribution of the cytoplasmic components and inclusions into layers in the order of their relative and decreasing specific gravity, as follows: (1) a layer of starch grains and plastids (when present in the cell); (2) a layer of mitochondria (plastidome and pseudo-chondriome); (3) a layer of cytoplasm (which is often quite free of various cytoplasmic components); (4) a layer of osmiophilic platelets (Golgi bodies of Bowen); (5) a layer composed of, or formed by, the fusion of vacuoles and (6) a layer of lipoid material. Thus, it is evident from this study that the osmiophilic platelets are discrete

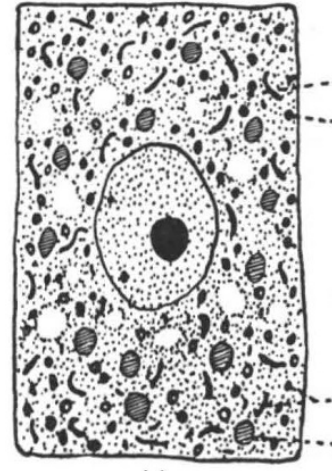

(a)

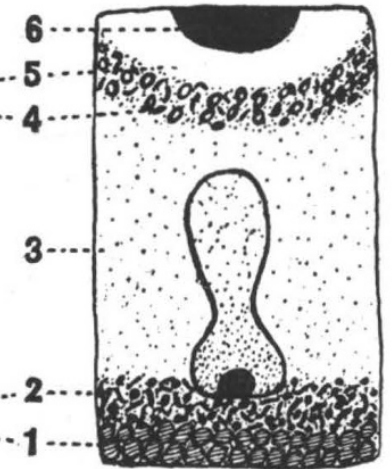

(b)
F'IG. 1.

structures in plant cytoplasm, and differ greatly in specific gravity from the plastids and mitochondria.

The nucleus is frequently stretched in the direction of the centrifugal force with the nucleolus constituting its heaviest component. In extreme cases, the nucleolus is thrown completely out of the nucleus centrifugally.

Zoology Department,

Trinity College, Dublin.

H. W. Beams.

Zoology Department, State University of Iowa.

R. L. KrNG.

\section{Some Recent Atomic Weight Determinations}

IN conjunction with Mr. H. S. Patterson, a number of new determinations of the limiting ratios of certain gases with oxygen have been carried out, using an improved microbalance apparatus in which errors due to adsorption have been eliminated. A more detailed account of the apparatus and results will be published elsewhere.

The gases used were nitrous oxide, ethylene, carbon dioxide and carbon tetrafluoride. The measurements obtained from these gases lead to the following values of the atomic weights:

$$
\begin{aligned}
& \mathrm{N}_{\mathrm{N}_{2} \mathrm{O}}=14 \cdot 006(8) . \mathrm{C}_{\mathrm{C}_{2} \mathrm{H}_{4}}=12 \cdot 012(2) . \\
& \mathrm{C}_{\mathrm{CO}_{2}}=12 \cdot 010(1) . \mathrm{F}_{\mathrm{CF}_{4}}=18 \cdot 995 .
\end{aligned}
$$

The compressibilities at $21^{\circ} \mathrm{C}$. of the gases can be calculated from the data and are appended below in comparison with the values obtained on an Andrew's compression apparatus ${ }^{1}$.

\begin{tabular}{lcc}
\multicolumn{1}{c}{ Gas } & $\begin{array}{c}A_{21}{ }^{\circ} \mathrm{c} . \\
\text { microbalance }\end{array}$ & $\begin{array}{c}A_{21}{ }^{\circ} \mathrm{c} . \\
\text { Nitrous oxide }\end{array}$ \\
0.00559 & 0.00567 \\
Ethylene & 0.00636 & 0.00612 \\
Carbon dioxide & 0.00522 & 0.00526 \\
Carbon tetrafluoride & 0.00418 & 0.00420
\end{tabular}

Whilst the values of nitrogen and fluorine are in close agreement with the accepted values, carbon 